\title{
The recycling of furniture and the sustainable development research
}

\author{
Lin Yuan ${ }^{1}$,Jianzhong Huang ${ }^{2 a}$,liangchao Gou $^{2 b}$ \\ ${ }^{1}$ School of Design and Arts, Beijing institute of Technology, Beijing 100081, China; \\ ${ }^{2}$ Sichuan hanjulige household co., LTD, No. 559 Tongxin road, Chongzhou, Sichuan province, \\ 611200, China.

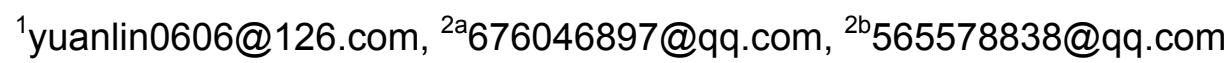

Keywords: Furniture Structure, Recycling, Nature Environmen, Furniture Recycling.

\begin{abstract}
Wood is the main material of furniture industry, To make ends meet of forest area, due To the huge demand of lumber. In the face of the deteriorating ecological environment, to replace wood and improve the life cycle of lumber is imperative. For traditional furniture, wood always are indispensable. Thus increasing the use of wood cycle problem becomes particularly. This article from the perspective of sustainable development, this paper investigates the existing furniture recycling use, and recycling of the problem. According to these problems puts forward the three main factors of furniture recycling, that is modular structure, fixed assembly method, and the material of relatively fixed. Through the study to the structure of the wardrobe kind of furniture, the recycling scheme of this kind of furniture is put forward.
\end{abstract}

\section{Introduction}

As the world's population increased year by year, the natural environment is facing serious challenges to the survival of humans, over the past century the world forest area is reduced by about a quarter, serious destruction of ecological environment, and direct threat to the survival of mankind. And trees for the protection of natural environment and maintaining ecological balance is acting a very important role. Through the research of Plants and related environmental protection expert shows that the environmental value of forest a year per square kilometer between $\$ 170000$ to $\$ 800000$; There are many for plants to the protection of the environment. In addition to producing oxygen and absorbing the dust in the air, carbon dioxide and other harmful substances, can also be less fresh air, reduce noise, beautify the environment, and so on. On the condition of meet the market demand, the cycle of furniture can be used to reduce the demand for new products. To prolong the lifecycle of the timber, reduce the use of wood, realize the sustainable development of furniture industry.

\section{The Chinese market at present stage of furniture and timber demand situation analysis}

In China, Wood as the main material of furniture has a history of thousands of years. Besides beautiful and durable, wood furniture also has the regulation of indoor environment. China in recent decades, with living standard improved steadily, the demand for the furniture rising Rapidly.

China has become a furniture production country in the world, and is also an important part of the furniture consumption. China has a population of 1.3 billion, a huge consumer market has attracted worldwide attention. According to statistics, annual for one person, the furniture cost is $\$ 371$ in the United States, Germany people spending \$236 in furniture, furniture cost is \$371 in Japan. Because of China's big population base, the current Chinese furniture is spending about $\$ 30$ per capita, around $\$ 39$ billion in total consumption, and the demand of furniture is growing year by year, as shown in figure 1. 


\begin{tabular}{|l|c|c|c|}
\hline & $\begin{array}{l}\text { Per capita } \\
\text { consumption } \\
\text { of furniture }\end{array}$ & $\begin{array}{l}\text { Annual per } \\
\text { capita income }\end{array}$ & $\begin{array}{l}\text { Furniture } \\
\text { consumption } \\
\text { and income } \\
\text { ratio(\%) }\end{array}$ \\
\hline China & 30 & 4260 & 0.7 \\
\hline Japan & 371 & 42440 & 0.85 \\
\hline South Korea & 164 & 19890 & 0.82 \\
\hline Germany & 236 & 47580 & 0.5 \\
\hline America & 371 & 42440 & 0.85 \\
\hline
\end{tabular}

Fig. 1. Major national furniture consumption and income ratio

According to the Chinese existing market of $\$ 39$ billion of furniture consumption. To the average amount calculated, $30 \%$ of the consumption for wood timber, the consumption is about $\$ 11.7$ billion a year; Calculate according to the average price of $\$ 900 / \mathrm{m}^{3}$, the amount is about 13 million $\mathrm{m}^{3}$. To meet the demond of 13 million $\mathrm{m}^{3}$ wood, need to cut down about $3600 \mathrm{sq} . \mathrm{km}$. of forest every year, much bigger than the taihu lake area. These forests originally can make between $\$ 500$ million to $\$ 2$ billion the environmental value a year. In today's ecological environment is imminent, The loss of environmental value is often need us more to repay.

\section{The using of furniture recycling situation analysis in present China.}

With the living standard improved steadily in recent 20 years, the consumers have greater demand to furniture. On the one hand, the furniture manufacturing industry consume a large amount of natural resources and energy; On the other hand, our country high-end furniture consumers throw millions of furniture, such as tables, chairs, beds, cabinets. A large number of high quality wood in using of making furniture, but the recovery rate of furniture is very low. According to statistics, only $10 \%$ of recycling furniture to keep its original function, $45 \%$ for paper making raw materials, $35 \%$ as fuel, $10 \%$ other features also low level of use, as shown in figure 2. Furniture product design without considering its disassembly recycling performance, lack of related parts and materials, it is difficult toseprate the useful materials and parts from the useless, also make a lot of reusable components can't reuse effectively, even though some product can be removed and recovered, but the price of cost has make the recycling unvaluable. If you can't improve the original function of furniture recycling and to meet the demand of part of the furniture market, the sustainable development of furniture industry cannot be implemented.

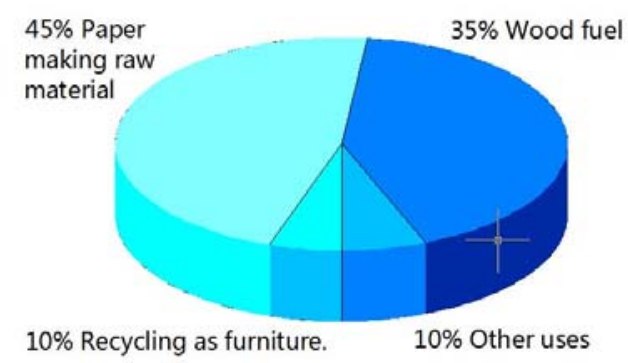

Fig. 2. Furniture recycling ratio in various ways

\section{Furniture recycling}

To mention the recycle of furniture, can be traced back to the Ming and qing dynasties in ancient China, the Ming and qing furniture has always had a good tradition, the concept of recycling. A set of furniture mostly be used through one generation to another. And the damage furniture will be disassembled into components for sale, also for other furniture's repair. The recycle of furniture has been widely used in Ming and qing period. 
Through the analysis of the Ming and qing furniture found the following characteristics. First, highly modular furniture structure; Second, fixed assembly structure and assembly method; Third, the relatively fixed timber species. So the Ming and qing furniture can achieve complete separation of components, and be classified according to the materials and types. All of these ensure the recycle of Ming and qing furniture. In view of the characteristics of the Ming and qing furniture, Find the three conditions of furniture implementation cycle use, that is the modular structure, fixed assembly method, and the relatively fixed material, as shown in figure 3.

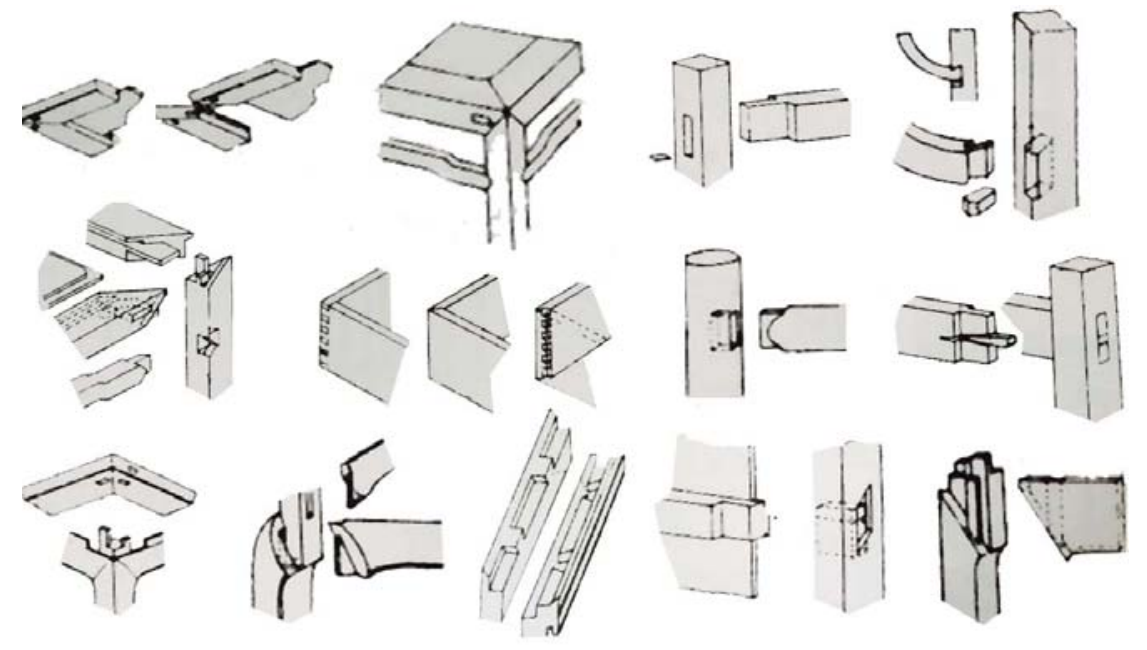

Fig. 3. Ming 's type furniture components and structure

Through the study, the standardization of good structure and assembly design of furniture , can reduce $30 \%$ of the manufacturing cost, at the same time, can improve the productivity about $150 \%$, also can improve the repeating utilization rate of $30 \%$. In this case, it is particularly important, through the modular design for furniture can decrease the cost, save resource, reduce pollution, increase the recycle ratio of furniture.

\section{Conductive to the recovery and secondary utilization of structure preliminary design}

At present, the furniture style is varied, to realize the general structure design standardization must separate the furniture style design and structure design, furniture style design depends on the standardization of the structure of the system. Style is ever changing but never from the structure of the standard. Furniture modular design is the primary question to solve the problems of design rather than style design problems.

Through the enlightenment of the research in the Ming and qing furniture structure, can be summed up the following: first, f Furniture components assembly way to have reversibility, that is the components can be installed firmly and intact into parts unwounded. And this process can be repeated many times. Second, the size of furniture as far as possible to realize modularization, and a reduction in the number of standard components; Non-standard components measurement using a mix of standard parts and non-standard widget. Third, in terms of material, Exposed plate and style interprets parts should use real wood material as many as possible, The cabinet body use man-made board material as many as possible. Fourth, furniture style interpretation will divide into the modelling and the pattern, modelling is standardized as far as possible, patterns should be attached to the standard component, which is easy to replace.

The following, in order to demonstrate the four basic points mentioned above, we ues the storage furniture for a example. 

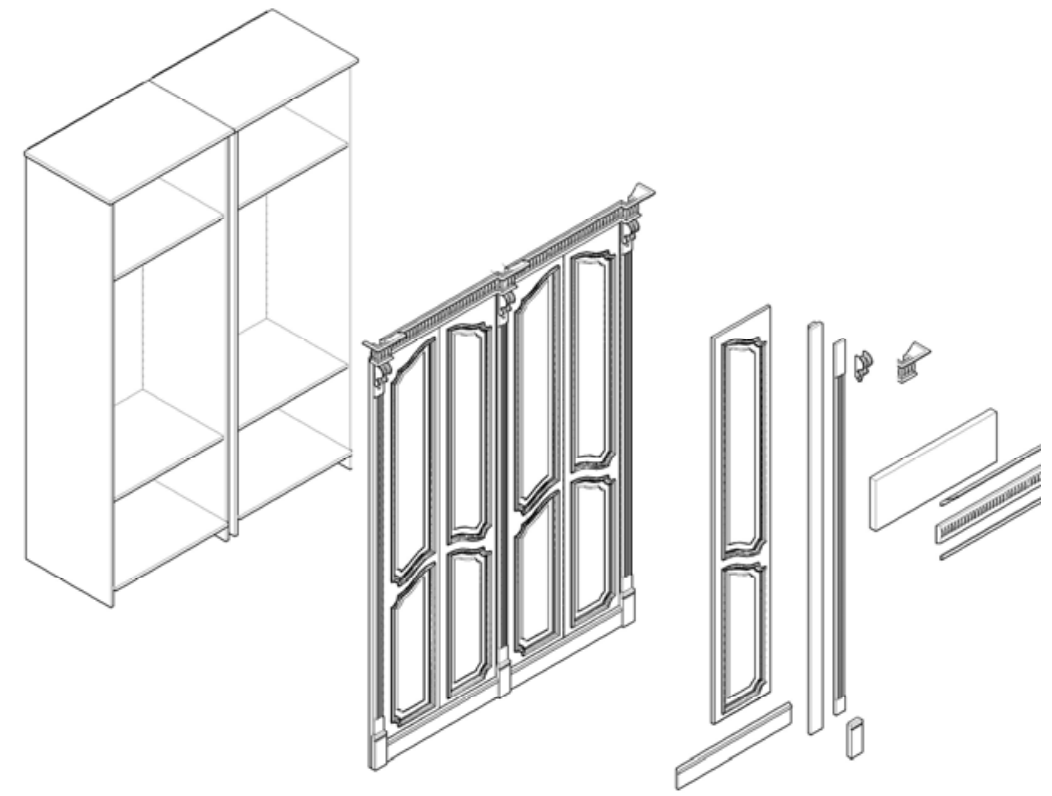

Fig. 4. Four door wardrobe design

As shown in figure 4 , is a set of four door wardrobe. First seprate the furniture into two parts of the cabinet body and the surface decoration parts. Surface decoration parts containsdoor, line, column, and the leakage board, also line include the top line, waist line, Skirting board, etc. Surface decoration component, generally made from rare wood, The cabinet body parts material is commonly man-made board. As shown in figure 5, that is the cabinet body, surface decoration and its component. Superficially this cabinet with no difference to other cabinet, but the difference of this cabinet to others is the standardization of cabinet body and components.

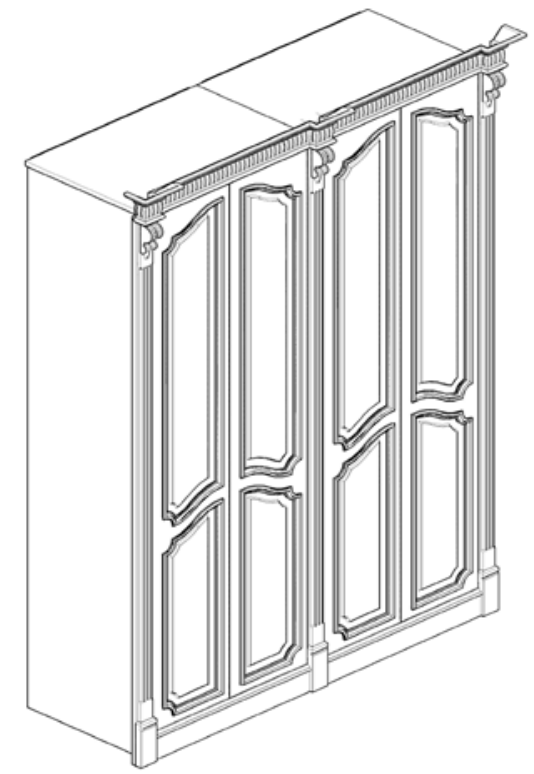

Fig. 5. The wardrobe body, surface decoration and its components

First of all, the size of the cabinet body and the cabinet door is not arbitrary, the width of the cabinet door is only $400 \mathrm{~mm}, 450 \mathrm{~mm}, 500 \mathrm{~mm}$, the height of the cabinet door is only $2200 \mathrm{~mm}$, $1600 \mathrm{~mm}, 800 \mathrm{~mm}, 150 \mathrm{~mm}, 600 \mathrm{~mm}, 1000 \mathrm{~mm}, 200 \mathrm{~mm}$. Width and height of the cabinet body is according to the combination of standard size of cabinet door, the depth of the cabinet body has four different sizeis as $300 \mathrm{~mm}, 400 \mathrm{~mm}, 500 \mathrm{~mm}, 600 \mathrm{~mm}$. Through these module can make the difference of size in $100 \mathrm{~mm}$ of all kinds of cabinets, I define it as decimeter level basic size adjustment.

Second, on both sides of the cabinet body can choose to add decorative column, the width of the column is $40 \mathrm{~mm}, 60 \mathrm{~mm}$ or $80 \mathrm{~mm}$, through the column can realize width adjustment above $20 \mathrm{~mm}$, 
Add the top line and skirting board to achieve highly direction adjustment, above and below the cabinetbody, I define the adjustment at this level as a centimeter level basic size adjustment,
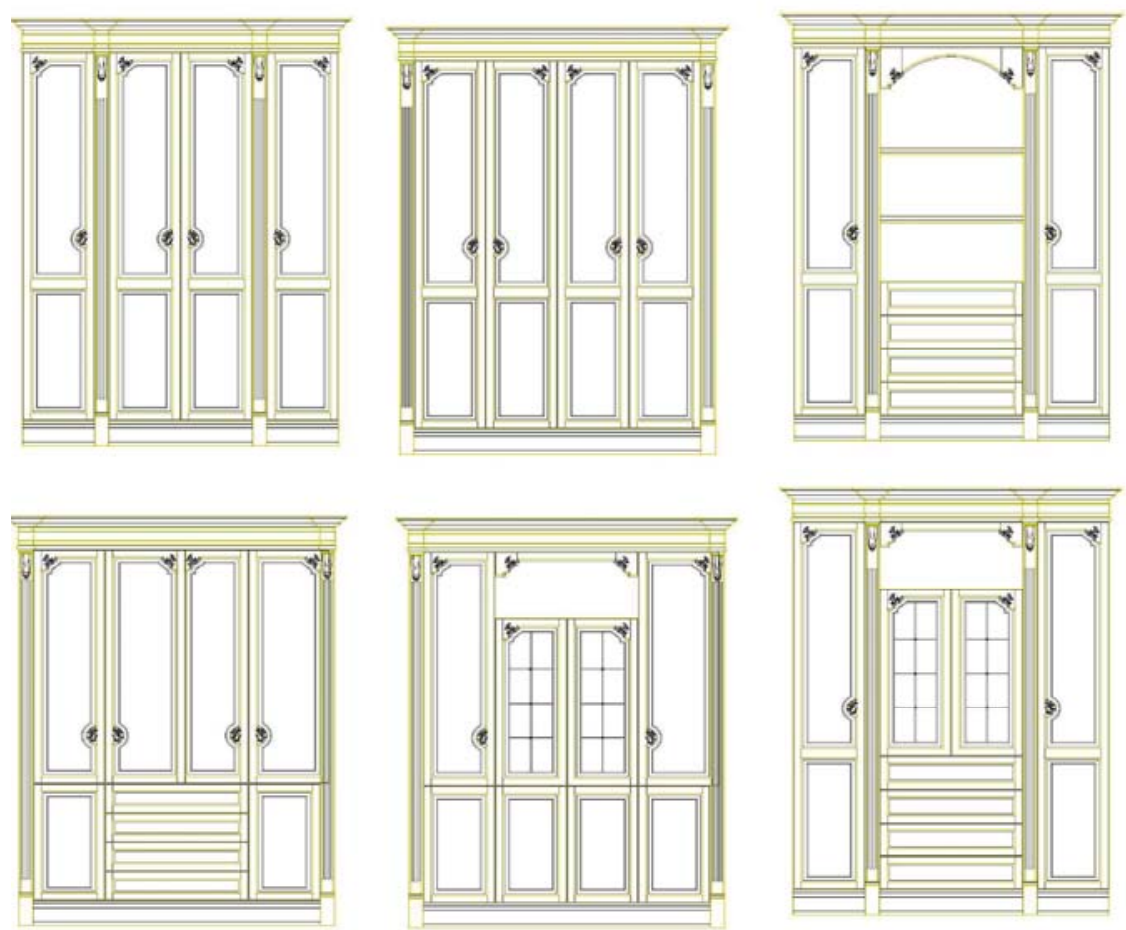

Fig. 6. The schematic of the standard four door cabinet combination way

Finally, on the back of decorative columns, as well as the top line and skirting board has a no shape tablet, the tablet can be custom processing non-standard sizes, I define it as millimeter level basic size adjustment.

Through the combination of different sizes of standard cabinet body, achieve decimeter level basic size adjustment in the direction of the width and height; By adding different width of column and the roof line, waist line, skirting board to realize the centimeter level adjustment; Through the adjustment of the specific plate to achieve millimeter level adjustment. Through the above adjustment method can meet the different needs of consumers to the cabinet size, As shown in figure 6.

\section{Summary}

On the basis of modular structure, the surface of the cabinet door, the top line, column, stigma can be used for interpretation of the model and demonstrate the component of the style. The whole cabinet design can be according to the consumer demand to split the whole into several small cabinets under the unit of the cabinet door, it can be realized only need to replace part of the adjustment plate; And update the whole cabinet style is without upending, unneed to change the cabinet body, only need to change the surface decoration modeling artifacts. And replace the component can also be refurbished, used for secondary sales.

\section{References}

[1] Wang shanshan, Sun fangli, Duan xinfang, Zhao jingfeng. Wood waste recycling technology and the research emphasis in the future.[J]. Journal of northwest forestry college, 2005, 20 (2) : 13-18.

[2] $\mathrm{Hu}$ Jingchu. Development of ecology furniture to promote green consumption [J].Furniture and interior decoration, 2000, (6) : $12 \sim 14$.

[3] Chen zengbi. Research on Ming's type furniture [M]. Beijing, China building industry press, 2002.

[4] Keil B.New forest feeds producer needs[J].Wood Based Panels International, 1994, (7):27-29 